\title{
In search of a viable IAU-OAD Regional Node: A case for Africa
}

\author{
B. I. Okere, D. C. Okoh, I. A. Obi, P. N. Okeke and F. E. Opara
}

Centre for Basic Space Science, University of Nigeria Nsukka. www.cbssonline.com

\begin{abstract}
The establishment of the IAU Office of Astronomy for Development (OAD) in Cape Town, South Africa, with the aim of using astronomy to stimulate development at all levels including primary, secondary and tertiary education, science research and the public understanding of science is a welcome development to consolidate the gains of IYA2009. To assist the IAU OAD office in achieving its goal of using astronomy as a tool for development, there is need to have OAD regional nodes. In this paper, we present the astronomy activities/programs required of such a Regional Node in Africa and how the Node can play a significant role to realise the vision of Astronomy for a better world!
\end{abstract}

